\author{
Т.М. Глазырина
}

\title{
СЕНСОМОТОРНЫЕ РЕАКЦИИ МУЖЧИН ПРИЗЫВНОГО ВОЗРАСТА С АРТЕРИАЛЬНОЙ ГИПЕРТЕНЗИЕЙ
}

Аннотация. В статье рассмотрены сенсомоторные реакции у мужчин призывного возраста с артериальной гипертензией. Существующая система профессионального отбора, ориентированная на использование бланковых психологических методик показала свою эффективность, тем не менее, во многих случаях целесообразно дополнительно исследовать психофизиологическое характеристики призывника. В частотности, по результатам психофизиологического исследования можно судить об уровне нервно-психической устойчивости призывника. При артериальной гипертензии психофизиологические изменения определяются раньше клинических проявлений, что взаимосвязано со снижением нервно-психической устойчивости. В исследовании приняло участие 128 человек. Методология исследования основана на проведении сравнительного анализа в группах.

У обследованных с артериальной гипертензией 1 степени во время стрессовой нагрузки определяется более низкая сбалансированность процессов торможения и возбуждения в центральной нервной системе. $B$ условиях стресса у обследованных с артериальной гипертензией 1 степени определяется большая цена деятельности, определяется большее количество ошибочных действий.

Ключевые слова: артериальная гипертензия, призывник, сенсомоторная реакция, психофизиологический тест, вариабельность проб, точность восприятия времени, стресс-тестирование, баланс нервных процессов, цена деятельности, ошибочные действия.

Abstract. The research deals with the study of sensomotor reactions demonstrated by men of military age who suffer from arterial hypertension. The existing system of professional selection focused on the use of blank psychological techniques has proved to be efficient, however, in many cases it is advisable to further investigate the psycho-physiological characteristics of a recruit. In particular, based on the results of psychophysiological research it is possible to define the level of neuropsychological stability of a recruit. In cause of a recruit suffering from arterial hypertension physiological changes are determined before manifestation of clinical symtoms which correlates to a decreased level of neuro-psychological stability. 128 respondents participated in the research. The research methodology is based on the comparative analysis of results. Men with the first-degree arterial hypertension demonstrated a worse balance of inhibitory and excitative processes during stress. They also demonstrated a higher value of activity and made more action errors.

Key words: operation cost, stress testing, balance of the nervous processes, accuracy of time perception, psychophysiological test, variability of the samples, sensomotor reactions, recruit, arterial hypertension, action errors.

B оенная служба является особым видом деятельности, предъявляющая к человеку повышенные требования, как физические, так и психологические $[1 ; 2]$.

Существующая система профессионального отбора, ориентированная на использование бланковых психологических методик показала свою эффективность, тем не менее во многих случаях целесообразно дополнительно исследовать психофизиологическое характеристики призывника $[1 ; 3 ; 4]$. В частности, по результатам психофизиологического исследования можно судить об уровне нервно-психической устойчивости призывника (НПУ) [5; 6]. Высокая НПУ способна обеспечить высокую эффективность функционирования человека в сложных условиях, часто при наличии витальной угрозы. При этом стрессоустойчивость препятствует формированию также и психосоматических заболеваний, в числе которых ведущее место занимает артериальная гипертензия $[7 ; 8 ; 9]$.

Повышение артериального давления - это нормальная реакция человека на стресс, однако, при нарушении психической регуляции происходит стойкое его повышение с формированием заболевания. Показано, что при артериальной гипертензии психофизиологические изменения определяются раньше клинических проявлений [8], что 
Клиническая психология

Таблица 1.

Сравнительный анализ результатов теста точности восприятия времени обследованных

\begin{tabular}{|c|c|c|}
\hline Показатель & Группа 1 (Норма) (x \pm s) & $\begin{array}{c}\text { Группа } 2 \\
(A \Gamma 1)(x \pm s)\end{array}$ \\
\hline Точность восприятия времени в покое, \% & $69,20 \pm 10,66$ & $68,94 \pm 11,30$ \\
\hline Вариабельность проб в покое & $7,72 \pm 3,00$ & $6,30 \pm 2,70^{*}$ \\
\hline Точность восприятия времени, стресс, \% & $70,01 \pm 10,63$ & $65,94 \pm 11,69 *$ \\
\hline Вариабельность проб, стресс & $7,23 \pm 2,71$ & $6,08 \pm 2,53^{*}$ \\
\hline
\end{tabular}

Примечания: * - различия в группах статистически значимы.

Таблица 2.

Сравнительный анализ простой сенсомоторной реакции обследованных

\begin{tabular}{|c|c|c|}
\hline Показатель & Группа 1 (Норма) (x \pm s) & $\begin{array}{c}\text { Группа } 2 \\
(A Г 1)(x \pm s)\end{array}$ \\
\hline Скорость ПСМР в покое, мС & $315,27 \pm 101,72$ & $330,97 \pm 166,38$ \\
\hline Вариабельность времени в покое & $5,42 \pm 3,40$ & $4,79 \pm 3,15$ \\
\hline Скорость ПСМР, стресс, МС & $328,07 \pm 49,50$ & $437,68 \pm 329,06^{*}$ \\
\hline Вариабельность времени, стресс & $6,01 \pm 2,70$ & $4,24 \pm 2,76^{*}$ \\
\hline
\end{tabular}

Примечания: * - различия в группах статистически значимы.

может свидетельствовать о снижении НПУ и о необходимости проведения психопрофилактических мероприятий.

\section{Организация и методы исследования}

Обследовано 128 мужчин призывного возраста от 18 до 26 лет, из них $\mathrm{n}=65$ с нормальными и оптимальными показателями АД (САД 110-129 / ДАД 75-84 мм рт. ст.) (1 группа); $\mathrm{n}=63$ с АГ 1 степени (САД 140-159 / ДАД 90-99) (2 группа).

Использовались следующие психофизиологические тесты: тест на точность восприятия времени, простая сенсомоторная реакция (ПСМР), сложные сенсомоторные реакции (ССМР): «Светофор», «Экзамен», в условиях дефицита времени. Психофизиологическое исследование проводили дважды: в состоянии функционального покоя и во время стресс-тестирования. Вариабельность проб и реакций определяли как величина равная отношению среднего значения к стандартному отклонению. Вариабельность проб и реакций отражает степень разброса проб от среднего. Чем выше показатель вариабельности, тем «кучнее» обследованный выполнял тест, тем более сбалансированы процессы торможения и возбуждения в ЦНС.

Сравнительный анализ проводился с использованием критерий $\mathrm{t}-$-тьюдента. Различия считали статистически значимыми при $\mathrm{p}<0,05$.

\section{Результаты и обсуждение}

Результаты теста точности восприятия времени и вариабельность проб в состоянии покоя и во время стресс-тестирования представлены в таблице 1.

Выявлено, что точность восприятия времени во время стресс-тестирования, а также вариабель- ность проб точности восприятия времени в покое и во время стресс-тестирования статистически значимо $(\mathrm{p}<0,05)$ выше у обследованных с нормальными показателями АД.

Восприятие времени человеком обусловлено сочетанием трёх факторов: 1) скорость протекания обменных процессов в головном мозге; 2) восприятие собственных вегетативных процессов и произвольных движений как внутренний эталон времени; 3) система социальных эталонов времени, развившаяся в культуре.

В состоянии функционального покоя точность восприятия времени у обследованных одинакова, однако, у людей с АГ 1 степени разброс значений точности варьирует статистически значимо $(\mathrm{p}<0,05)$ в более широких пределах, что указывает на более низкую согласованность факторов обуславливающих чувство восприятия времени. Данная ситуация усугубляется при проведении стресс-тестирования, сочетаясь статистически значимо $(\mathrm{p}<0,05)$ со снижением точности восприятия времени. Что может свидетельствовать о большей цене деятельности человека с АГ 1 степени в условиях стресса.

Результаты скорости простой сенсомоторной реакции и вариабельность времени в состоянии покоя и во время стресс-тестирования представлены в таблице 2.

Выявлено, что обследованные с нормальным уровнем АД статистически значимо $(\mathrm{p}<0,05)$ быстрее реагировали на зрительный сигнал и «кучнее» выполняли тест во время стресстестирования, что свидетельствует о большей сбалансированности процессов торможения и возбуждения в ЦНС по сравнению с обследованными с АГ во время стрессовой нагрузки.

В состоянии функционального покоя обследованные с нормальными показателями АД и с 
Сравнительный анализ сложной сенсомоторной реакции

Таблица 3. с дифференцировкой «Светофор» и «Экзамен» обследованных

\begin{tabular}{|c|c|c|}
\hline Показатель & Группа 1 (Норма) (x \pm s) & $\begin{array}{c}\text { Группа } 2 \\
(A \Gamma 1)(x \pm s)\end{array}$ \\
\hline ССМР «Светофор», в покое, МС & $622,73 \pm 636,78$ & $558,68 \pm 122,89$ \\
\hline ССМР «Светофор», стресс, мс & $553,87 \pm 160,94$ & $578,77 \pm 129,46$ \\
\hline ССМР «Экзамен», в покое, мс & $2205,68 \pm 1168,92$ & $2140,08 \pm 825,61$ \\
\hline ССМР «Экзамен», стресс, мс & $2140,94 \pm 1049,64$ & $2217,29 \pm 873,03$ \\
\hline
\end{tabular}

Сравнительный анализ сложной сенсомоторной реакции

Таблица 4. с дифференцировкой в условиях дефицита времени обследованных

\begin{tabular}{|c|c|c|}
\hline Показатель & 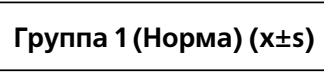 & $\begin{array}{c}\text { Группа } 2 \\
(A \Gamma 1)(x \pm s)\end{array}$ \\
\hline Скорость ССМР в покое, МС & $671,71 \pm 138,57$ & $905,08 \pm 214,40^{*}$ \\
\hline Вариабельность времени в покое & $3,11 \pm 1,16$ & $2,39 \pm 0,91 *$ \\
\hline Скорость ССМР, стресс, МС & $632,34 \pm 107,63$ & $782,63 \pm 148,72^{*}$ \\
\hline Вариабельность времени, стресс & $3,44 \pm 1,10$ & $2,64 \pm 1,12^{*}$ \\
\hline Количество ошибок в покое & $7,09 \pm 1,76$ & $9,54 \pm 2,22 *$ \\
\hline Количество ошибок, стресс & $7,38 \pm 1,58$ & $8,86 \pm 1,81^{*}$ \\
\hline
\end{tabular}

Примечания: * различия в группах статистически значимы.

АГ 1 степени по времени ПСМР и её вариабельности не различались. Однако, во время стресстестирования обследованные с АГ 1 степени статистически значимо $(\mathrm{p}<0,05)$ имели большее время реакции и больший разброс значений. Что указывает на рассогласование состояния возбуждения и торможения в головном мозге с преобладанием торможения.

Следует отметить, что время ССМР с дифференцировкой «Светофор» и «Экзамен» не различались статистически значимо ни в состоянии функционального покоя, ни при стресстестировании (табл. 3), что объясняется, вопервых, влиянием «тренировки» в процессе выполнения (Светофор - около 60 стимулов, Экзамен - около 120), и, во-вторых, более высокой значимостью каждого стимула ПСМР (10 стимулов), что повышало очевидно уровень эмоционального напряжения обследуемых в большей степени, чем ССМР.

Результаты скорости сложной сенсомоторной реакции с дифференцировкой в условиях дефицита времени (ДВ), вариабельность времени и количество ошибок в состоянии покоя и во время стресс-тестирования представлены в таблице 4.

Выявлено, что обследованные с нормальным уровнем АД статистически значимо ( $<<0,05)$ быстрее реагировали на зрительный сигнал как в состоянии покоя, так и во время стресстестирования. Также обследованные с нормальным уровнем АД статистически значимо $(\mathrm{p}<0,05)$ «кучнее» выполняли тест как в состоянии покоя, так и во время стресс-тестирования, что свидетельствует о большей сбалансированности процессов торможения и возбуждения в ЦНС по сравнению с обследованными с АГ. Так же обследованные с нормальным уровнем АД статистически значимо $(\mathrm{p}<0,05)$ делали меньше ошибок при выполнении теста, что свидетельствует о более высокой работоспособности обследованных с нормальными показателями АД.

Обследованные обеих групп показали одинаковую динамику в процессе выполнения сложной сенсомоторной реакции с дифференцировкой в условиях дефицита времени. Так, во процессе стресс-тестирования время реакции в обеих группах уменьшилось, точность проб повысилась, это может быть связано с несколькими причинами, обусловленными тренировкой:

1) Известно, что всякий новый раздражитель сначала вызывает ориентировочную реакцию с более или менее обширной и длительной иррадиацией возбудительного процесса по коре больших полушарий, которая затем сменяется фазой концентрации. По мере повторения раздражителя имеет место привыкание, которое сопровождается всё менее выраженной иррадиацией возбуждения с одновременным повышением динамичности возникающих нервных процессов. Постепенная редукция фазы иррадиации и достижение определённого уровня хронической (или статической) концентрации возбудительного процесса в коре, по-видимому, и являются одной из важнейших причин укорочения времени реакции в процессе тренировки.

2) Вторая причина, тесно связанная с первой, состоит в нарастающей по мере упрочения 
условных связей, стойкости корковых очагов возбуждения.

3) Третья причина связана с изменением самой структуры временных связей, заменой более сложных второсигнальных ассоциаций более простыми первосигнальными.

\section{Выводы}

1) У обследованных с АГ 1 степени определяется более низкая согласованность факто- ров, обуславливающих чувство восприятия времени.

2) У обследованных с АГ 1 степени во время стрессовой нагрузки определяется более низкая сбалансированность процессов торможения и возбуждения в ЦНС.

В условиях стресса у обследованных с АГ 1 степени определяется большая цена деятельности, выявляется большее количество ошибочных действий.

\section{Список литературы:}

1. Глазырина Т.М., Ятманов А.Н., Юсупов В.В., Ятманова Т.М. Патогенетические особенности влияния отношения к болезни и артериального давления на нервно-психическую адаптацию военнослужащих // Клиническая патофизиология. 2014. № 2. С. 36-39.

2. Дорофеев И.И., Корзунин В.А., Овчинников Б.В. и др. Методологические аспекты выделения категории медико-психологического сопровождения курсантов // Клиническая и специальная психология. 2016. Т. 5. № 2. С. $113-120$. [Электронный ресурс] DOI: 10.17759/psyclin.2016050208.

3. Лобачев А.В., Ятманова Т.М., Ятманов А.Н. Использование методики биологической обратной связи для диагностики устойчивости к стрессу и уровня психической адаптации курсантов // Здоровье-основа человеческого потенциала: проблемы и пути их решения. 2012. Т. 7. № 1. С. 127-128.

4. Овчинников Б.В., Дьяконов И.Ф., Богданова Л.В. Психологическая предпатология: превентивная диагностика и коррекция. СПб.: ЭЛБИ-СПб, 2010. 366 с.

5. Порожников П.А., Федоров Е.В., Ятманов А.Н. Прогнозирование заболеваемости военнослужащих военно-морского флота в зависимости от вида деятельности // Новая наука: От идеи к результату. Стерлитамак: РИЦ АМИ, 2016. № 1-2 (60). С. 16-18.

6. Солодков А.С., Федоров Е.В., Днов К.В. и др. Совершенствование системы профессионального психологического отбора специалистов ВМФ // Учёные записки университета имени П.Ф. Лесгафта. 2015. № 12 (130). С. 318-322.

7. Солодков А.С., Юсупов В.В., Днов К.В. и др. Медико-психологическое сопровождение кандидатов на поступление в военный вуз // Учёные записки университета имени П.Ф. Лесгафта. 2015. № 5 (123). С. 258-263.

8. Солодков А.С., Юсупов В.В.,Днов К.В. и др. Медико-психологическое сопровождениевоеннослужащих в военном вузе // Учёные записки университета имени П.Ф. Лесгафта. 2015. № 5. С. 254-258.

9. Ятманов А.Н. Патогенетические детерминанты внутренней картины болезни у пациентов с эссенциальной гипертензией: Дис. ... канд. мед. наук. СПб.: ГОУ ВПО «Военно-медицинская академия», 2010. 147 с.

\section{References (transliterated):}

1. Glazyrina T.M., Yatmanov A.N., Yusupov V.V., Yatmanova T.M. Patogeneticheskie osobennosti vliyaniya otnosheniya k bolezni i arterial'nogo davleniya na nervno-psikhicheskuyu adaptatsiyu voennosluzhashchikh // Klinicheskaya patofiziologiya. 2014. № 2. S. 36-39.

2. Dorofeev I.I., Korzunin V.A., Ovchinnikov B.V.i dr. Metodologicheskie aspekty vydeleniya kategorii mediko-psikhologicheskogo soprovozhdeniya kursantov // Klinicheskaya i spetsial'naya psikhologiya. 2016. T. 5. № 2. S. 113-120. [Elektronnyi resurs] DOI: $10.17759 /$ psyclin.2016050208

3. Lobachev A.V., Yatmanova T.M., Yatmanov A.N. Ispol'zovanie metodiki biologicheskoi obratnoi svyazi dlya diagnostiki ustoichivosti k stressu i urovnya psikhicheskoi adaptatsii kursantov // Zdorov'e-osnova chelovecheskogo potentsiala: problemy i puti ikh resheniya. 2012. T. 7. № 1. S. 127-128.

4. Ovchinnikov B.V., D'yakonov I.F., Bogdanova L.V. Psikhologicheskaya predpatologiya: preventivnaya diagnostika i korrektsiya. SPb.: ELBI-SPb, 2010. $366 \mathrm{~s}$.

5. Porozhnikov P.A., Fedorov E.V., Yatmanov A.N. Prognozirovanie zabolevaemosti voennosluzhashchikh voenno-morskogo flota v zavisimosti ot vida deyatel'nosti // Novaya nauka: Ot idei k rezul'tatu. Sterlitamak: RITs AMI, 2016. № 1-2 (60). S. 16-18.

6. Solodkov A.S., Fedorov E.V., Dnov K.V. i dr. Sovershenstvovanie sistemy professional'nogo psikhologicheskogo otbora spetsialistov VMF // Uchenye zapiski universiteta imeni P.F. Lesgafta. 2015. № 12 (130). S. 318-322.

7. Solodkov A.S., Yusupov V.V., Dnov K.V. i dr. Mediko-psikhologicheskoe soprovozhdenie kandidatov na postuplenie v voennyi vuz // Uchenye zapiski universiteta imeni P.F. Lesgafta. 2015. № 5 (123). S. 258-263.

8. Solodkov A.S., Yusupov V.V., Dnov K.V.i dr. Mediko-psikhologicheskoe soprovozhdenie voennosluzhashchikh v voennom vuze // Uchenye zapiski universiteta imeni P.F. Lesgafta. 2015. № 5. S. 254-258.

9. Yatmanov A.N. Patogeneticheskie determinanty vnutrennei kartiny bolezni u patsientov s essentsial'noi gipertenziei: Dis. ... kand. med. nauk. SPb.: GOU VPO «Voenno-meditsinskaya akademiya», 2010. 147 s. 